AC 2011-339: INCORPORATING PROBLEM BASED LEARNING AND
CASE STUDIES IN LAB COURSES: STUDENT PERCEPTIONS AND ED-
UCATIONAL BENEFITS FOR THIS TEACHING PEDAGOGY

Cindy Waters, North Carolina A\&T State University (Eng)

Stephanie Luster-Teasley, North Carolina A\&T State University

Dr. Stephanie Luster-Teasley is a tenure-track assistant professor with a joint appointment between the Departments of Civil, Architectural, Agricultural and Environmental Engineering and the Department of Chemical Engineering. She has a BS in Chemical Engineering from North Carolina A\&T State University, a MS in Chemical Engineering from Michigan State University, and a PhD in Environmental Engineering from Michigan State University. She specializes in physical and chemical remediation processes for water and soils. Her educational research focuses on improving Engineering Education for minority and female students. Prior to joining North Carolina A\&T State University, she was a private consultant at two consulting firms specializing in chemical oxidation remediation for soil and water remediation. 


\section{Incorporating Problem Based Learning and Case Studies in Lab Courses: Student Perceptions and Educational Benefits for this Teaching Pedagogy}

During the fall and spring of 2009-2010, an introductory environmental engineering course was re-designed to include four new environmental laboratory modules that use an inquiry-based "open" experiment for enhanced student learning. This research was funded through the NSF Innovations in Engineering Education (IEECI) program to develop modules utilizing the pedagogy of problem-based learning and case studies to teach new environmental sustainable design concepts. Problem based learning (PBL) and case studies are novel approaches for laboratory modules. In PBL and case studies, students are assigned real-world problems to discuss, research, and solve as teams. This method diverges from the traditional "step-by-step" method currently used in laboratory courses and provides the opportunity for students to use the concepts they learn to develop new ideas for engineering systems.

Pre-surveys consisted of the on-line Learning Styles Inventory developed by Felder and a baseline student achievement learning gains (SALG) on-line assessment. ${ }^{1,2,3}$ Using the class average for learning styles, $68.4 \%$ of the students preferred active learning, $84.2 \%$ preferred sensing, $89.5 \%$ preferred visual, and $72.2 \%$ were sequential learners. The pre-SALG instrument results demonstrated the students had a limited understanding of sustainability and Green Engineering concepts. The instrument also indicated the students were enthusiastic about the subject. Students during the pre-assessment indicated they were not familiar with problem-based learning mode of teaching and this method had not been implemented in any of the prior courses.

At the completion of the semester, students completed the post-SALG survey, a postsurvey Assessment of Student Preferences for Teaching and Learning, and an ABET Based Questionnaire for Course Assessment. A problem arose with the on-line post SALG survey and too few students completed the survey so that data for the post-SALG could not be statistically evaluated. The Assessment of Student Preferences for Teaching and Learning Survey provided results indicating students were in favor of incorporating problem based learning in to the classroom as a tool for instruction, felt they developed a stronger understanding of sustainability, and enjoyed the use of case studies; however $83 \%$ of the class agreed or strongly agreed they preferred lectures by the professor. This result may be explained by examination of the models of cognitive development developed first by Piaget and later adapted more towards college students by Perry. Prior courses treated the students very much as dualistic thinkers, in that all knowledge comes from a greater authority and all is either right or wrong ${ }^{4}$. Teachers in previous courses supplied all of the information in an organized manner and because of the learning stage of the students they were comfortable being given all of the information. As a student moves from a dualist to relativist epistemologies they are able to form their own opinions and better build their own knowledge. This perception of students is also evidenced in the focus group interviews that were performed at the conclusion of the semester. Students spoke on their perceived level of engagement compared to other labs they have taken and the instructor style. This paper will address the psychology and the results gleaned from the use of problem based learning in a laboratory course. 


\section{Introduction}

Students demonstrate different learning styles and PBL and case study teaching methods provide an instructional method that can help meet the needs of the various learning styles identified by Felder-Silverman Model ${ }^{2,3}$. This research therefore seeks to begin a way of redesigning laboratory courses that promote active learning. The hands-on laboratory environment, educational innovations, the student's personal experience, and metacognitive skills hence will lead to learning gains.

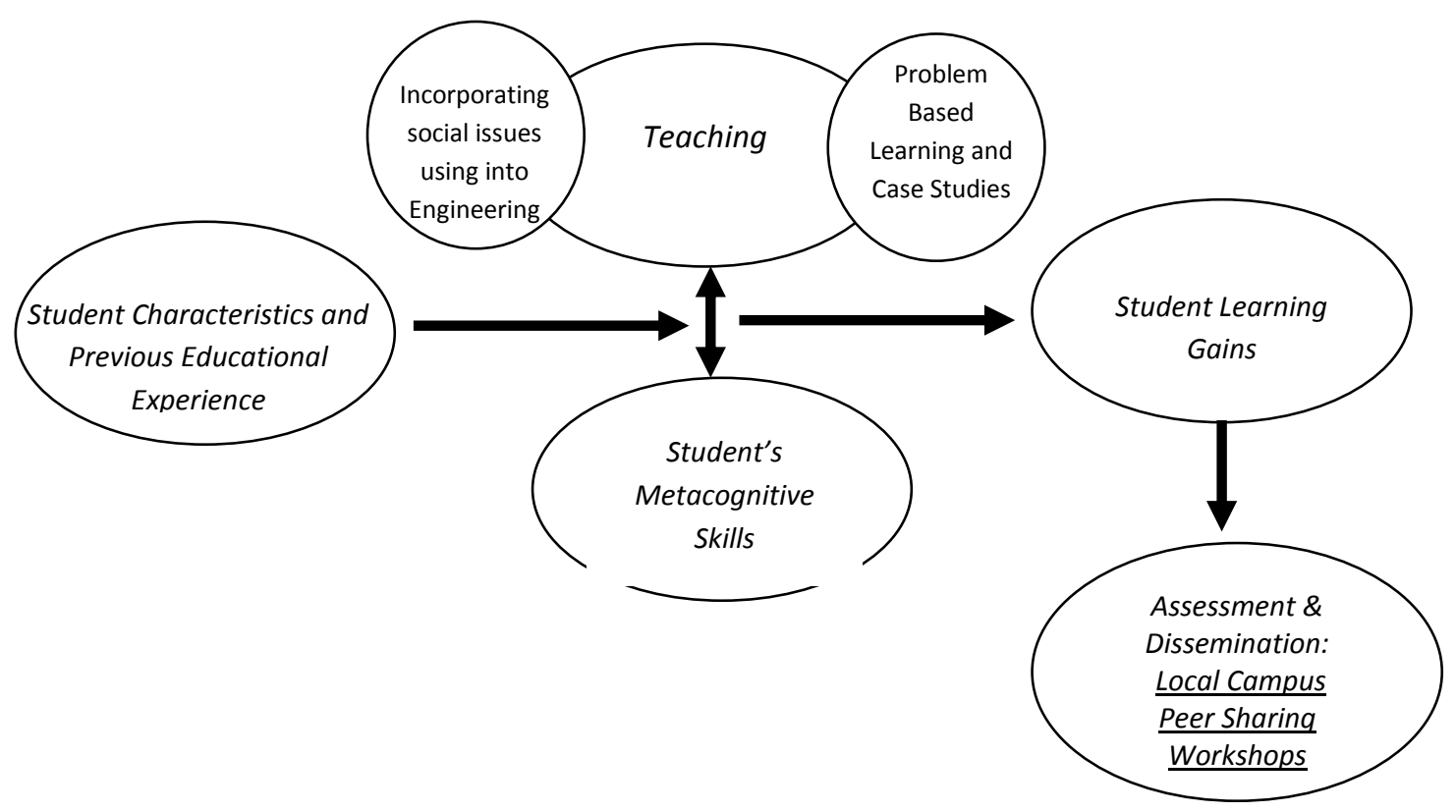

Figure 1. Conceptual Framework for ENE Laboratory Module Reform

This semester this course was taught the CIEN 311 Environmental Laboratory course had an enrollment of eighteen students. The students were junior, Civil Engineering majors. The demographics consisted of fourteen males, two females, and was $56 \%$ minority (i.e. African American, African, Hispanic). The course was divided in to modules to help "repackage" the lab activities.

\section{Modules and Assessments}

\section{Module 1: Sustainable Engineering and Green Design}

Sustainability is one of the newest paradigm shifts for engineering design. There are a number of new "green" buildings currently being built in many cities, on-line resources, and 
texts for shifting building design to use concepts that are more environmentally friendly. This 4week module will discuss the concepts of sustainability and green design.

Module 2: Rainwater Harvesting, Water Recycling, and Reuse

Water use and the sustainability of water supplies represent a few of the challenging issues being faced by Environmental Engineers. As recently as the summer of 2007, a number of southern states, such as North Carolina, faced drought conditions which lead to water restrictions. Water resources in the western US historically have been limited and require engineered systems to provide adequate water supplies. Internationally, third world communities have limited access to safe drinking water. As the demand for water supplies reaches critical limits, water reclamation and reuse have become attractive options for water supplies. For this four week module, students will learn the traditional water quality analysis conducted in an environmental engineering course. They will study the technologies needed to ensure water supplies are safe for human consumption and use.

\section{Module 3: Biodegradable Materials}

Packaging material and plastic comprises of $38 \%$ of the materials sent to landfills. The US is calculated to be the highest contributor to landfill waste and the most wasteful country in the world. Biodegradable materials are materials that can be degraded by microorganisms. These materials provide an option for reducing the amount of landfill waste because they are able to degrade in aerobic and anaerobic microbial conditions. For this 4 week module, students will learn about microbial degradation of biodegradable materials. In the module, students will make items from biodegradable polymers and study their degradation in a composting system.

\section{Module 4: Solid Waste Recycling}

Recycling is a method to reduce the amount of material being sent to landfills. In this module, students will initially build a foundation for traditional solid waste management. This module will include a tour of the Greensboro Solid Waste Transfer Station and Landfill. This tour will give them the opportunity to see the items that could be recycled that are sent to landfills. Using this traditional foundation for solid waste management and disposal, students will conduct a recycling audit for the campus. The two week module will include an analysis of recycling activities and the development of a plan for recycling on campus or a case study such as recycling and disposal of Hurricane Katrina solid waste.

\section{Assessments}

1. Index of Learning Styles Survey (ILSS)

2. Student Assessment of Learning Gains Instrument (SALG)

3. Student Reports/Presentations of Green Building Module 1, Water recycling (Module 2), Biodegradable polymers and Recycling (Modules 3 and 4).

4. Comprehensive Exam for Sustainable design, modules, and understanding lab concepts for analyzing air, water, and soil samples. 


\section{ASSESSMENT: INDEX OF LEARNING STYLES}

Students completed the Index of Learning Styles (ILSS) and the pre-SALG assessment in January 2010. The ILSS survey results averaging the learning styles for the entire class. The ILSS uses a ranking scale from 1 to 11 indicating a student's possible preferences or possible strengths for a particular type of learning style. This is an increasing scale for learning preferences with 1 representing the low end of the scale and 11 representing the highest level of preference for a learning style. The student's learning style preferences were evaluated individually and then averaged together to give an overall class learning style preference. Table 1 provides a definition for each of the learning styles. Table 2 compares the class average for the learning preferences. Using the class average for learning styles, $68.4 \%$ of the students preferred active learning, $84.2 \%$ preferred sensing, $89.5 \%$ preferred visual, and $72.2 \%$ were sequential.

Table 1. Summary of Learning Styles (http://www.engr.ncsu.edu/learningstyles)

ACTIVE LEARNERS tend to understand and learn information best by doing something active such as discussing or applying the material.

REFLECTIVE LEARNERS are learners who prefer to think about material before applying the material learned in a course.

SENSING LEARNERS prefer to learn facts and solve problems by well established methods.

INTUITIVE LEARNER prefer to investigate possibilities and relationships. These learners are more comfortable with abstractions and mathematical formulations.

VISUAL LEARNERS learn by seeing pictures, diagrams, flow charts, films, and demonstrations.

VERBAL LEARNERS learn more by written and spoken explanations.

SEQUENTIAL LEARNERS tend to learn using linear steps in a logical order or pattern.

GLOBAL LEARNERS learn by understanding the "big picture" and then linking concepts.

Table 2. Comparison of the overall class averaged learning styles

\begin{tabular}{|c|c|c|c|c|c|c|c|}
\hline Active & Reflective & Sensing & Intuitive & Visual & Verbal & Sequential & Global \\
\hline $68.4 \%$ & $31.6 \%$ & $84.2 \%$ & $15.8 \%$ & $89.5 \%$ & $10.5 \%$ & $72.2 \%$ & $27.8 \%$ \\
\hline
\end{tabular}

Figure $2 \mathrm{a}-\mathrm{d}$ compare the eight learning styles identified by in Richard Felder and Barbara Soloman ${ }^{3}$. The graphs show the preference level and the number of students with that preference. The engineering students in the course tended to prefer active, sensing, and visual learning. Interestingly, the sequential and global learning preferences appeared to have a 
Gaussian Bell distribution. The ILSS assessment will be evaluated further to determine learning style preferences based on gender and ethnicity.

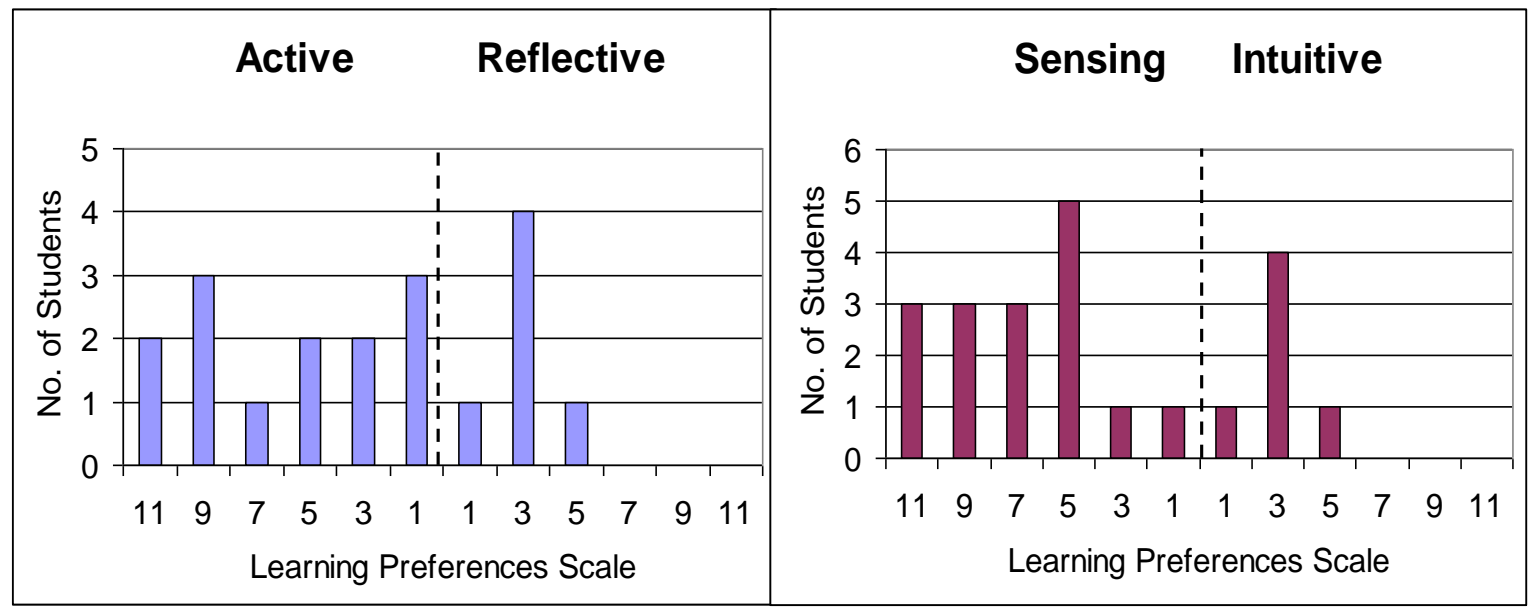

(a)

(b)

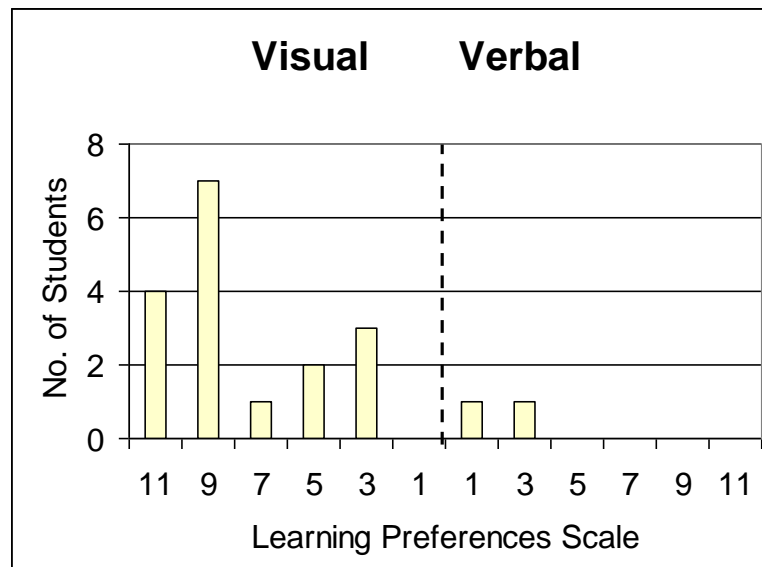

(c)

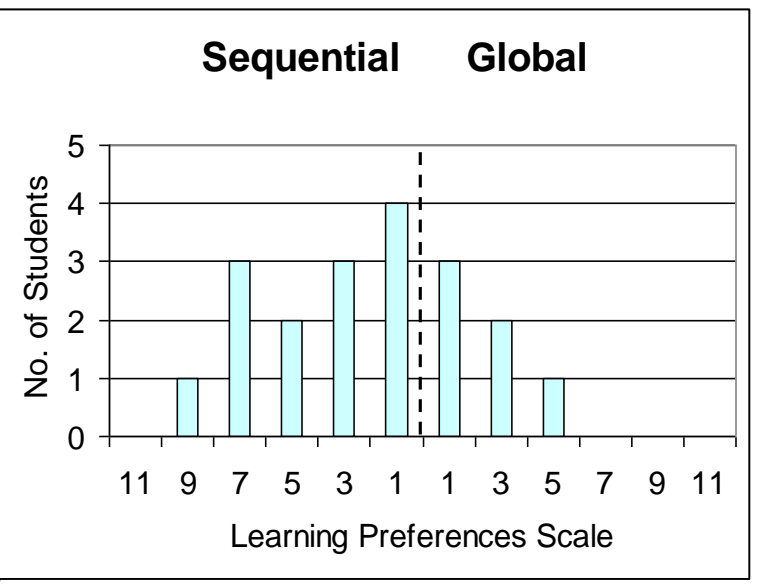

(d)

Figure 2. Graphs of the Learning Preferences for Students in Environmental Engineering Course and the number of students with the learning style preference. (a) Active vs. Reflective, (b) Sensing vs. Intuitive, (c) Visual vs. Verbal, and (d) Sequential vs. Global

\section{What does this mean to improving learning?}

The class as a whole favors active, sensing, visual, and sequential learning patterns. However when looking at the individual learning styles for the students their profiles show a mix of learning styles. Individual learning styles may be address by PBL and case study teaching methods because this method allows the individual student to learn from the instructor, peers, 
and as an individual student researching and mastering material. Active learners could benefit by actively participating in lab, hands-on activities. Reflective learners can use the PBL and case studies to reflect over the case background or the framework story associated to the module activities. The research or fact gathering opportunity the students conduct while developing their sustainable designs would facilitate learning for students who are sensing learners. Intuitive learners can use the case studies and PBL to investigate possible sustainable ideas and "what if" scenarios in their designs. Visual and verbal learners receive both types of learning styles during the module. Sequential learners may find the case studies and PBL difficult because of their need to see linear steps in a logical order, however, real world problems do not always start in a linear or stepwise fashion. As future engineers, students are taught to develop and use mathematical models to design real world systems but this can only be done after understanding the global aspects of a problem. Global learners through the PBL and case studies can see the "big picture" of the module and what the activity ultimately is trying to accomplish in overall learning.

\section{Student Assessment Learning Gains (SALG)}

In January of the semester a SALG - Student Assessment of their Learning Gains survey was created for the lab course ${ }^{1}$. The questions went through several iterations and the Instrument \#14271, CIEN 311 Environmental Engineering Laboratory, was administered in January 2010. The pre-assessment was successfully implements using the SALG on-line tool. The postassessment on-line had an error that prevented the students from completing the survey on-line. Only one student was able to successfully access the on-line tool. Survey Monkey will be used in the future and an attempt will be made to recapture student opinion for the post survey this Fall 2010 .

The table displayed is a list of the questions and when the question was of the type "Select one" the choices were:

1: not applicable, 2: not at all, 3: just a little, 4: somewhat, 5: a lot, 6: a great deal

Table 1: Pre-course survey instrument with results.

\begin{tabular}{|l|l|l|l|l|l|}
\hline Number & Question & Type & $\mathbf{N}$ & Mean & Std dev \\
\hline & Understanding & Category & & & \\
\hline 1 & Presently, I understand... & Category & & & \\
\hline 1.1 & The following concepts that will be explored in this class & Category & & & \\
\hline 1.1 .1 & Green Buildings and Green Design & Select one & 12 & 4.8 & 0.87 \\
\hline 1.1 .2 & Rainwater harvesting, Water reuse, and water recycling & Select one & 12 & 4.5 & 1.09 \\
\hline 1.1 .3 & Solid waste and biodegradable materials & Select one & 12 & 4.1 & 0.90 \\
\hline 1.1 .4 & Solid waste recycling & Select one & 12 & 4.0 & 0.95 \\
\hline 1.2 & The relationships between those main concepts & Select one & 12 & 4.1 & 1.00 \\
\hline
\end{tabular}




\begin{tabular}{|c|c|c|c|c|c|}
\hline 1.3 & $\begin{array}{l}\text { How ideas we will explore in this class relate to ideas I } \\
\text { have encountered in other classes within this subject area }\end{array}$ & Select one & 12 & 4.2 & 1.06 \\
\hline 1.4 & $\begin{array}{l}\text { How ideas we will explore in this class relate to ideas I } \\
\text { have encountered in classes outside of this subject area }\end{array}$ & Select one & 12 & 3.9 & 0.90 \\
\hline 1.5 & $\begin{array}{l}\text { How studying this subject helps people address real world } \\
\text { issues }\end{array}$ & Select one & 12 & 4.8 & 1.03 \\
\hline \multirow[t]{2}{*}{1.6} & $\begin{array}{l}\text { What do you expect to understand at the end of the class } \\
\text { that you do not know now? }\end{array}$ & Long answer & 11 & & \\
\hline & Skills & Category & & & \\
\hline 2 & Presently, I can... & Category & & & \\
\hline 2.1 & $\begin{array}{l}\text { Find articles relevant to a particular problem in } \\
\text { professional journals or elsewhere }\end{array}$ & Select one & 12 & 4.9 & 1.00 \\
\hline 2.2 & Critically read articles about issues raised in class & Select one & 12 & 4.8 & 1.22 \\
\hline 2.3 & Identify patterns in data & Select one & 12 & 4.4 & 0.79 \\
\hline 2.4 & $\begin{array}{l}\text { Recognize a sound argument and appropriate use of } \\
\text { evidence }\end{array}$ & Select one & 12 & 5.0 & 0.60 \\
\hline 2.5 & Develop a logical argument & Select one & 12 & 4.8 & 0.75 \\
\hline 2.6 & $\begin{array}{l}\text { Write documents in discipline-appropriate style and } \\
\text { format }\end{array}$ & Select one & 12 & 4.2 & 0.83 \\
\hline 2.7 & Work effectively with others & Select one & 12 & 5.2 & 0.75 \\
\hline 2.8 & Prepare and give oral presentations & Select one & 12 & 4.7 & 1.23 \\
\hline \multirow[t]{2}{*}{2.9} & $\begin{array}{l}\text { What do you expect to be able to do at the end of the } \\
\text { course that you cannot do now? }\end{array}$ & Long answer & 7 & & \\
\hline & Attitudes & Category & & & \\
\hline 3 & Presently, I am... & Category & & & \\
\hline 3.1 & Enthusiastic about the subject & Select one & 12 & 5.0 & 0.95 \\
\hline 3.2 & $\begin{array}{l}\text { Interested in discussing the subject area with friends or } \\
\text { family }\end{array}$ & Select one & 12 & 4.8 & 0.94 \\
\hline 3.3 & $\begin{array}{l}\text { Interested in taking or planning to take additional classes } \\
\text { in this subject }\end{array}$ & Select one & 12 & 5.2 & 1.03 \\
\hline 3.4 & Confident that I understand the subject & Select one & 12 & 4.8 & 1.14 \\
\hline
\end{tabular}




\begin{tabular}{|c|c|c|c|c|c|}
\hline 3.5 & Confident that I can do this subject & Select one & 12 & 5.2 & 0.45 \\
\hline 3.6 & Comfortable working with complex ideas & Select one & 12 & 5.0 & 0.85 \\
\hline 3.7 & $\begin{array}{l}\text { Willing to seek help from others (teacher, peers, TA) } \\
\text { when working on academic problems }\end{array}$ & Select one & 12 & 5.4 & 0.79 \\
\hline 3.8 & $\begin{array}{l}\text { Please comment on your present level of interest in this } \\
\text { subject. }\end{array}$ & Long answer & 10 & & \\
\hline & Integration of learning & Category & & & \\
\hline 4 & Presently, I am in the habit of... & Category & & & \\
\hline 4.1 & $\begin{array}{l}\text { Connecting key ideas I learn in my classes with other } \\
\text { knowledge }\end{array}$ & Select one & 12 & 5.0 & 0.60 \\
\hline 4.2 & Applying what I learn in classes to other situations & Select one & 12 & 5.2 & 0.62 \\
\hline 4.3 & Using systematic reasoning in my approach to problems & Select one & 12 & 5.1 & 0.67 \\
\hline 4.4 & $\begin{array}{l}\text { Using a critical approach to analyzing data and arguments } \\
\text { in my daily life }\end{array}$ & Select one & 12 & 4.9 & 0.51 \\
\hline 4.5 & $\begin{array}{l}\text { Please comment on how you expect this material to } \\
\text { integrate with your studies, career, and/or life? }\end{array}$ & Long answer & 8 & & \\
\hline
\end{tabular}

The responses from the preliminary assessment sought to measure a baseline for the students' opinion for their understanding, skills, attitudes, and integration of learning. The goal was to determine if there were changes in the student responses from the beginning of the course compared to the end of the course. Due to the error during the post survey administration, this data cannot be used to provide an assessment of improvements in student opinion. We will use the student interviews and the additional post surveys.

\section{Teaching/Learning Preferences and ABET Post Assessment}

Two additional post surveys were conducted in conjunction with the SALG. The surveys were designed to assess the benefit of various teaching techniques, interventions, and tools. In the first survey (Table 4) the students were asked to Strongly Agree, Agree, Neutral, Disagree, or Strongly Disagree to the teaching/learning method benefited their learning. The second survey (Table 5) is the ABET based assessment conducted for the course. The surveys for student's preferences for teaching and learning and the student's opinion of their learning gains produced a number of interesting results. Only twelve of the nineteen students elected to complete the final surveys. Examples from the from the survey where nine or more students strongly agreeing on teaching and learning methods suggested that the students benefited from communicating about environmental engineering and sustainability with group members, class discussions led by the professor, and use of electronic resources and computers for research. The students also strongly 
agreed they benefited by thinking critically about environmental engineering and communicating and solving problems related to environmental technology, air, water, and soil. Students responding to the survey agreed or were neutral for working individually on assignments and class discussions led by classmates. For the learning gains students indicated they felt "somewhat knowledgeable" in areas such as design and testing of environmental experiments and broad education necessary to understand the impact of engineering solutions in a global and societal context. We would have liked to have seen more students indicate they felt "very knowledgeable" in these areas. Students felt "very knowledgeable" in environmental engineering and sustainability definitions and concepts and understanding professional and ethical responsibilities.

These surveys provided feedback for student perception about their skill abilities by the end of the course. This survey appears to be a better assessment tool than the questions from the SALG, therefore, during our evaluation and assessment to improve the course we may decide to use this instrument to help with both pre and post-assessment.

\section{Interviews}

On the last day of class a set of group interviews were administered. The script and questions are shown below and we are working to transcribe the responses and code the answers. The questions were generated after referring to the General Accounting office reference titled, "Using Structured Interviewing Techniques".

Questions asked to students:

1. This semester Dr. Teasley has re-created your lab going away from a step-by-step laboratories to a more problem based strategy.

2. So that we can improve the process for future semesters, I would like to ask you some questions

a. Do you feel that you are less or more engaged in this course material than you would have been if this had been a traditional step-by-step lab?

b. How could we improve the modules for sustainability and sustainable green building design, water recycling and reuse? Biodegradable polymers was originally one of the additional modules, do you believe by adding biodegradable polymers it would be beneficial?

c. Do you believe that adding solid waste management topics would be beneficial? Are there other topics where you would like to see more emphasis?

The interviews were recorded according to the IRB approval and will be coded to document the student responses during the interview. Preliminary feedback from the students suggests they felt the case studies and problem-based methods used in the course were more engaging compared to 
their traditional classes. The students particularly enjoyed the real world approaches and the relationships to engineering concepts and how they could expect to apply classroom learning to their real jobs after graduation. They felt some aspects of the labs were similar to the traditional lab format, yet the problem based learning and real-life scenarios added a new spin on the topics that made them more interesting. The students recommended that the course could be improved by having more time outside of the classroom for site visits and field visits. The class groups felt they looked at a wide variety of similar topics and felt if under the "umbrella" of the topic such as green engineering if each group focused on one specific area for the topic and then presented the material to the class they would have the opportunity to go into more depth.

\section{Closing}

The course could be improved by having more time outside of the classroom for site visits and field visits. The class groups felt they looked at a wide variety of similar topics and felt if under the "umbrella" of the topic such as green engineering if each group focused on one specific area for the topic and then presented the material to the class they would have the opportunity to go into more depth. The original goal of the course was to offer Green Engineering, Water Recycling, Biodegradable Polymers, and Solid waste handling. Due to time constraints in the amount of time the case study/PBL method needed, we would have had difficulty trying to implement all four modules during year 1 . Now that we are in year 2 , the first two modules are developed and we expect to be able to add the polymer and solid waste/recycling modules. Students during the interview indicated they did not feel that biodegradable polymers would be an interesting topic. After year 2 activities in the course, which will include the polymer, solid waste/recycling sessions we will determine the benefits in using all four modules or focusing on select modules. 


\section{References:}

1. http://www.salgsite.org/

2. Felder, R. and Silverman, L. "Learning and Teaching Styles in Engineering Education," Engr. Education, 78(7), 674-681 (1988).

3. Felder, R. and Brent, R., "Understanding Student Differences." J. Engr. Education, 94(1), 57-72 (2005).

4. Svinicki, Marilla, A Guidebook On Conceptual Frameworks For Research In Engineering Education, Rigorous Research in Engineering Education NSF DUE-0341127, DUE-0817461, 2010

5. General Accounting Office. (1991). "Using Structured Interviewing Techniques".. Washington, D.C.: Program Evaluation and Methodology Division (http://www.gao.gov/policy/10_1_5.pdf). 